\title{
Analysis on the Anesthesia Effects of Sevoflurane and Propofol on Laparoscopic Cholecystectomy
}

\author{
LI ZHEN PAN, J. WU1 ${ }^{1}, H$. LI AND H. MING* \\ Department of Anesthesiology, ${ }^{1}$ Department of Pharmacy, Shandong Second Provincial General Hospital, No. 4 Duanxingxi \\ Road, Jinan, Shandong 250022, China
}

Pan et al.: To Compare the Anesthesia Effects of Propofol and Sevoflurane in Laparoscopic Cholecystectomy

To compare the anesthesia effects of propofol and sevoflurane in laparoscopic cholecystectomy. 60 patients with laparoscopic cholecystectomy in our hospital from January 2019 to June 2020 were randomly divided into control group and observation group, 30 cases in each group. The control group was given total intravenous anesthesia (continuous infusion of propofol $6-8 \mathrm{mg} / \mathrm{kg} / \mathrm{h}$ during operation), while the observation group was given intravenous inhalation combined anesthesia (continuous inhalation of 1-2.5 $\%$ sevoflurane during operation). The vital signs, anesthesia time, recovery time and extubation time of the two groups after induction and at the end of operation were compared and the occurrence of agitation during anesthesia recovery period was recorded The changes of heart rate and blood pressure before and after agitation were analyzed. The results showed that there was no significant difference in anesthesia time, recovery time and extubation time between the two groups $(p>0.05)$; there was no significant difference in body temperature, oxygen saturation, mean arterial pressure and heart rate between the two groups after induction and at the end of operation $(p>0.05)$; compared with the control group, the average agitation score of the observation group was significantly higher and the difference was statistically significant $(p<0.05)$. There were 6 cases of restlessness in the control group (6/30) and 14 cases of restlessness in the observation group (14/30), the difference between the two groups was statistically significant $(p<0.05)$; before and after the emergence of restlessness, the blood pressure fluctuation rate and heart rate fluctuation rate changed significantly and the blood oxygen saturation decreased, with significant difference $(p<0.05)$. Sevoflurane inhalation anesthesia is more prone to emergence agitation than propofol intravenous infusion anesthesia. Intravenous anesthesia and inhalation anesthesia have their own advantages. If we fully grasp and make use of their characteristics in our work, we will make the patients wake up more smoothly and the anesthesia work more efficiently.

Key words: Laparoscopic cholecystectomy, anesthesia effects, propofol, sevoflurane, emergence agitation

Different anesthesia methods and anesthetics in laparoscopic cholecystectomy have theirownadvantages and disadvantages. Any anesthesia method and drug may have more or less effects on liver function. This effect may be negative ${ }^{[1]}$, or it may protect the liver ${ }^{[2]}$. Propofol is a commonly used intravenous anesthetic clinically. In recent years, studies have shown that it has a protective effect on heart and brain tissue after ischemia reperfusion injury ${ }^{[3,4]}$, but its effect on liver ischemia reperfusion injury remains to be determined. Diethyl ether in inhaled anesthetics has serious effects on liver function and has been hardly used. Nitrous oxide has very low toxicity as long as oxygen supply is maintained. The incidence of hepatitis was higher after anesthesia with flurane, the incidence of hepatitis when applying enflurane and isoflurane is much lower than that of halothane, and sevoflurane causes less liver damage. Studies have reported that sevoflurane significantly reduced the concentrations of aspartate aminotransferase (AST) and alanine transaminase (ALT) after hepatic ischemia reperfusion (IR) in rats, suggesting that clinical concentrations of sevoflurane can protect against hepatic IR injury ${ }^{[5]}$. At present, there are few reports on the anesthesia effects analysis of these two commonly used anesthetics in laparoscopic cholecystectomy. Therefore, the purpose of this study is to explore the clinical effect of propofol and sevoflurane in laparoscopic cholecystectomy. 60 patients who

*Address for correspondence

E-mail: scmingli@163.com 
underwent elective laparoscopic cholecystectomy in our hospital from January 2019 to June 2020 were selected for general anesthesia. The American Society of Anesthesiologists (ASA) classification I-II, age 20-65 y old, height 150-183 cm, weight 43-87 kg, 30 males and 30 females. Exclusion criteria: patients with severe liver and kidney dysfunction, history of severe cardiovascular and cerebrovascular diseases, history of mental illness, drug abuse and severe allergies. All patients received intramuscular injection of $0.5 \mathrm{mg}$ of atropine and $0.1 \mathrm{~g}$ of phenobarbital sodium 30 min before surgery. After patients entering the room, check their information, establish a venous channel (if necessary, build an additional venous channel), continuous monitoring of non-invasive blood pressure, electrocardiogram (ECG) monitoring, oxygen saturation, pulse, etc. Anesthesia induction method: All selected patients were given intravenous injections of fentanyl $3 \sim 4 \mu \mathrm{g} / \mathrm{kg}$, propofol $2 \sim 2.5 \mathrm{mg} / \mathrm{kg}$ and atracurium $0.8 \sim 1 \mathrm{mg} / \mathrm{kg}$ for induction of anesthesia. After the muscle block was complete, they were given orally and perform tracheal intubation (mechanical ventilation). A nasal temperature probe was connected to an endotracheal catheter to continuously monitor the patient's body temperature. Maintenance of intraoperative anesthesia: Inoperative anesthesia maintenance: the above 60 patients were randomly divided into two groups to receive two kind of general anesthesia maintenance: control group and observation group. The control group was treated with intravenous anesthesia (intraoperative continuous infusion of propofol 6-8 $\mathrm{mg} / \mathrm{kg} / \mathrm{h}$ ), while the observation group was treated with intravenous combined inhalant anesthesia (continuous inhalation of 1 to $2.5 \%$ sevoflurane during the operation). In addition, all patients received continuous intravenous pumping of $12-15 \mu \mathrm{g} / \mathrm{kg} / \mathrm{h}$ remifentanil and intermittent intravenous injection of atracuramide to regulate intraoperative analgesia and maintain muscle block. After closing the abdominal cavity, stop using atracuramide and intravenously inject the first dose of analgesic (butorphanol 10-20 $\mu \mathrm{g} / \mathrm{kg}$ ). All patients should stop pumping propofol or inhaling sevoflurane 5-10 min before the end of the operation. Continuously pump remifentanil 5-10 $\mu \mathrm{g} /$ $\mathrm{kg} / \mathrm{h}$ according to patient's physical condition until the end of the operation. After surgery, all patients were given assisted respiration to recover their spontaneous respiration. When spontaneous respiration occurred, $0.02 \mathrm{mg} / \mathrm{kg}$ of neostigmine and $0.01 \mathrm{mg} / \mathrm{kg}$ of atropine were injected intravenously to antagonize the residual effects of atracuramide. When the patient's swallowing and cough reflexes recover, the blood oxygen saturation $\left(\mathrm{SPO}_{2}\right)$ under suction is $>95 \%$ and the spontaneous breathing is restored well, the patient's tracheal tube can be removed after sputum suction. Connect the intravenous tube to the analgesic pump and send the patient back to the ward or anesthesia recovery room. The patient's body temperature after anesthesia induction and at the end of the operation; heart rate, mean arterial pressure and pulse oximetry at the end of the operation and the occurrence of agitation; Anesthesia time (from the start of induction to the cessation of use of anesthetic drugs), awakening time (from the withdrawal of anesthetic drugs to the time of eye opening), extubation time (from the withdrawal of anesthetic drugs to the time of tracheal tube removal); After anesthesia induction, three times of invasive mean arterial pressure (MAP) and heart rate were recorded continuously after the patient's blood pressure stabilized and the time interval of recording was $3 \mathrm{~min}$. Then the average values of the three times detection were taken as the baseline blood pressure and baseline heart rate of the patient. If MAP $<55 \mathrm{mmHg}$ or heart rate $<50$ beats/min during this period, the patients were excluded. When the surgeon starts to cut the skin, continuously record the patient's MAP and heart rates, with an interval of $3 \mathrm{~min}$ each time until the end of the laparotomy. Then take the average of all values as the average blood pressure and average heart rate of the patient during the skin incision. Finally, the blood pressure fluctuation rate and heart rate fluctuation rate are calculated according to the obtained data. The calculation formula is: blood pressure fluctuation rate $=($ average blood pressure-basal blood pressure $) /$ basal blood pressure; heart rate fluctuation rate= (average heart rate-basal heart rate)/basal heart rate; Occurrence and score of patients' agitation during anesthesia recovery period. The agitation score was estimated with the sedation agitation scale. A score of 1-4 was divided into sedation and 5-7 was divided into agitation. Specific indexes were shown in Table 1. Statistical analysis was performed using Statistical Package for the Social Sciences (SPSS) 20.0 software. Measurement data were expressed as mean \pm standard deviation $(\mathrm{x} \pm \mathrm{s})$, group $\mathrm{t}$ test was used for comparison between groups and $\chi^{2}$ test was used for comparison of enumeration data. $\mathrm{p}<0.05$ was considered statistically significant. The results showed that there was no significant difference in anesthesia time, recovery time and extubation time between the two groups $(\mathrm{p}>0.05)$, as shown in Table 2. 
TABLE 1: SEDATION AND RESTLESSNESS SCORE SHEET

\begin{tabular}{|c|c|c|}
\hline \multicolumn{3}{|c|}{ Non-restless } \\
\hline 1 point & Cannot be awakened & $\begin{array}{l}\text { The patient has a slight or no response to stimulation, unable to } \\
\text { communicate or obey instructions }\end{array}$ \\
\hline 2 points & Excessive sedation & $\begin{array}{c}\text { The patient can be waked up by physical stimulation but unable } \\
\text { to communicate and obey instructions, may have instinctive body } \\
\text { movements }\end{array}$ \\
\hline 3 points & Calm & $\begin{array}{l}\text { Difficult to wake up, call or gentle shaking can wake up but fall asleep } \\
\text { soon after stopping, the patient can follow some simple instructions }\end{array}$ \\
\hline 4 points & Quiet, cooperative & Quiet, easy to wake up, obey instructions \\
\hline \multicolumn{3}{|l|}{ Restless } \\
\hline 5 points & Restlessness & Anxiety, trying to get up, can follow instructions \\
\hline 6 points & Very restless & $\begin{array}{l}\text { Despite repeated verbal warnings and instructions, but unable to be quiet } \\
\text { and need to artificially restrict their activities }\end{array}$ \\
\hline 7 points & Dangerous agitation & $\begin{array}{c}\text { Trying to remove the tracheal tube and other internal catheters by } \\
\text { themselves, turning over and getting out of bed, unconsciously assaulting } \\
\text { the staff, need to forcibly restrict their activities }\end{array}$ \\
\hline
\end{tabular}

TABLE 2: COMPARISON OF ANESTHESIA TIME, RECOVERY TIME AND EXTUBATION TIME BETWEEN THE TWO GROUPS

\begin{tabular}{lcccc}
\hline Group & Case & Anesthesia time $(\min )$ & Recovery time $($ min) & Extubation time $($ min) \\
\hline Control group & 30 & $203.45 \pm 19.37$ & $7.88 \pm 1.26$ & $11.49 \pm 2.08$ \\
Observation group & 30 & $200.92 \pm 17.63$ & $8.26 \pm 1.19$ & $11.69 \pm 1.97$ \\
\hline
\end{tabular}

The results showed that there were no significant differences in body temperature, blood oxygen saturation, mean arterial pressure and heart rate between the two groups after induction and at the end of surgery ( $>0.05$ ), as shown in Table 3. The results showed that compared with the control group, the average agitation score in the observation group was significantly higher and the difference was statistically significant $(p<0.05)$. There were 6 cases of agitation in the control group $(6 / 30)$ and 14 cases of agitation in the observation group $(14 / 30)$ and the difference between the two groups was statistically significant $(\mathrm{p}<0.05)$, as shown in Table 4 .
Before and after the onset of agitation, the fluctuation rate of blood pressure and heart rate of patients in the wake stage of general anesthesia were significantly changed and the blood oxygen saturation decreased, significant differences $(p<0.05)$, as shown in Table 5. Agitation in patients awakening from general anesthesia is one of the common complications in clinical anesthesia work. In the 1960s, Eckenhoff et al. ${ }^{[6]}$ discovered this phenomenon in their research and pointed out that agitation during anesthesia recovery period is very common in children and it is also related to preoperative clinical medication.

TABLE 3: VITAL SIGNS OF PATIENTS IN THE TWO GROUPS AFTER INDUCTION AND AT THE END OF SURGERY

\begin{tabular}{|c|c|c|c|c|c|c|}
\hline Group & Case & Time & Body temperature $\left({ }^{\circ}\right)$ & SPO2 (\%) & MAP (mmHg) & HR (bpm/min) \\
\hline \multirow[t]{2}{*}{ Control group } & 30 & After induction & $36.2 \pm 0.50$ & $100.00 \pm 0.50$ & $96.10 \pm 10.40$ & $72.40 \pm 6.70$ \\
\hline & & End of surgery & $35.3 \pm 0.40$ & $100.00 \pm 0.50$ & $92.80 \pm 12.60$ & $71.50 \pm 7.20$ \\
\hline \multirow[t]{2}{*}{$\begin{array}{l}\text { Observation } \\
\text { group }\end{array}$} & 30 & After induction & $36.3 \pm 0.70$ & $100.00 \pm 0.50$ & $95.2 \pm 10.80$ & $72.7 \pm 6.40$ \\
\hline & & End of surgery & $35.0 \pm 0.60$ & $100.00 \pm 0.50$ & $93.1 \pm 11.10$ & $72.2 \pm 6.80$ \\
\hline
\end{tabular}

TABLE 4: COMPARISON OF PATIENTS' AGITATION BETWEEN THE TWO GROUPS

\begin{tabular}{lcccc}
\hline Group & Case & $\begin{array}{c}\text { Average agitation } \\
\text { score }\end{array}$ & Agitation & Incidence of agitation \\
\hline Control group & 30 & $3.18 \pm 0.45$ & 6 & $20.00 \%$ \\
Observation group & 30 & $5.29 \pm 0.37^{*}$ & $14^{*}$ & $46.67 \%^{*}$ \\
\hline
\end{tabular}


www.ijpsonline.com

TABLE 5: CHANGES OF BLOOD PRESSURE FLUCTUATION RATE AND HEART RATE FLUCTUATION RATE IN PATIENTS WITH AGITATION

\begin{tabular}{lccc}
\hline Group & BP fluctuation rate & HR fluctuation rate & blood oxygen saturation \\
\hline Before agitation & $27.72 \pm 8.61$ & $5.33 \pm 1.02$ & $99.80 \pm 0.60$ \\
After agitation & $43.48 \pm 10.10^{\#}$ & $9.73 \pm 1.15^{\#}$ & $97.20 \pm 0.80^{\#}$ \\
\hline
\end{tabular}

Note: Compared with the patient before agitation, the difference after agitation is $p<0.05$

The main clinical symptoms of patients with agitation during general anesthesia are: unconsciousness, yelling or moaning, inability to follow the instructions of medical staff, involuntary movement of limbs, removal of their own tracheal tubes, urinary catheters and drainage tubes, attacking the medical staff, it is necessary to artificially restrict their body movement or intravenously inject sedative drugs to make them quiet. After waking up, patients often have no impression of the occurrence of agitation. At present, there are many studies on agitation in patients awakening from general anesthesia, but the pathogenesis is still unclear. A number of studies have proved that inhaled anesthetics is an important cause of postoperative restlessness ${ }^{[7]}$. Inhaled anesthetics are widely used because they can maintain a good anesthetic state, have good controllability and have no drug accumulation in the body. Among them, sevoflurane has become one of the most commonly used inhalation anesthetics in clinical practice because of its rapid induction, rapid drug metabolism, short patient recovery, non-irritating gas, low liver toxicity and stable hemodynamics. Charlotte et $a .^{[8]}$ found that in children undergoing adenoid curettage induced and maintained by sevoflurane, the incidence of restlessness after anesthesia was as high as $62 \%$ and clonidine could not effectively prevent the occurrence of restlessness and the result of restlessness is not affected by different evaluation standards. When enflurane is used to maintain anesthesia during thoracotomy, the incidence of restlessness during recovery is as high as $60 \%{ }^{[9]}$. Leman et al. ${ }^{[10]}$ observed that the incidence of agitation during recovery from anesthesia caused by sevoflurane inhalation anesthesia was $18 \%$ and that of desflurane was as low as $7 \%$. The mechanism of postoperative restlessness caused by inhaled anesthetics is not requested. Sachdev et $a l .{ }^{[11]}$ believe that the neurological basis of restlessness during anesthesia recovery period may be the nerve circuits abnormality of the cortex or subcortical. The application of inhaled general anesthetics can make the patient wake up too fast. The recovery time is different in different areas of the central nervous system. When most of the cerebral cortex is in a state of inhibition, the subcortical center has recovered and local central sensitization occurs. This lack of functional integrity affects the patient's response and processing ability to external perception ${ }^{[12]}$. Under the influence of some external harmful stimuli, such as pain, the central nervous system appears to be overexcited, causing restlessness after general anesthesia. According to the results of this study inhalation anesthesia group had a significantly higher incidence of agitation intravenous anesthesia group, the reason is that propofol and fentanyl are currently widely used clinically ultrashort-acting intravenous anesthetics and narcotics analgesics, The reason is that propofol and remifentanil are ultra-short-acting intravenous anesthetics and narcotic analgesics that are currently widely used clinically. The mechanism is mainly through the central gamma-Aminobutyric acid (GABA) and its receptors. At the same time, propofol reduces the release of excitatory neurotransmitters, such as L-glutamate and L-aspartic acid, to inhibit double or multiple synaptic excitation $^{[13]}$; Remifentanil's analgesic effect is super strong and rapid; its half-life is very short (only 3 5 $\mathrm{min}$ ) and the use of remifentanil and propofol in general anesthesia produces a good synergistic effect. The involuntary restlessness of patients in the intravenous and inhalant group may be due to rapid awakening and different central recovery time. The subcortical center has been liberated while the cerebral cortex is still in a suppressed state and focal sensitization of the central nervous system occurs. This deficiency of functional integrity may affect the patient's response to sensation and processing ability ${ }^{[14]}$. Under the action of certain harmful stimuli, the central nervous system is overexcited, thus induced postoperative restlessness. In conclusion, inhaled sevoflurane anesthesia is more likely to produce agitation than intravenous propofol anesthesia in recovery period. Intravenous anesthesia and inhalation anesthesia have their own advantages, if fully grasping and taking advantage of their characteristics in practice, will make the patient wake up more stable, anesthesia work handier. 


\section{Acknowledgement:}

This work was supported by Shandong Second Provincial General Hospital, Shandong Provincial ENT Hospital.

\section{Conflicts of interest:}

The authors report no conflicts of interest.

\section{REFERENCES}

1. Hemmerling TM, Minardi C, Zaouter C, Noiseux N, Prieto I. Sevoflurane causes less arrhythmias than desflurane after offpump coronary artery bypass grafting: a pilot study. Ann Card Anaesth 2010;13(2):116.

2. Fan KT, Lee TH, Yu KL, Tang CS, Lu DV, Chen PY, et al. Influences of tramadol on emergence characteristics from sevoflurane anesthesia in pediatric ambulatory surgery. Kaohsiung J Med Sci 2000;16(5):255-60.

3. Galinkin JL, Fazi LM, Cuy RM, Chiavacci RM, Kurth CD, Shah UK, et al. Use of intranasal fentanyl in children undergoing myringotomy and tube placement during halothane and sevoflurane anesthesia. Anesthesiology 2000;93(6):1378-83.

4. Cohen IT, Finkel JC, Hannallah RS, Hummer KA, Patel KM. Rapid emergence does not explain agitation following sevoflurane anaesthesia in infants and children: a comparison with propofol. Pediatr Anesth 2003;13(1):63-7.

5. Cole JW, Murray DJ, McALLISTER JD, Hirshberg GE. Emergence behaviour in children: defining the incidence of excitement and agitation following anaesthesia. Pediatr Anesth 2002;12(5):442-7.

6. JE E, DH K, RD D. The incidence and etiology of postanesthetic excitment. A clinical survey. Anesthesiology 1961;22:667-73.

7. Lepouse C, Lautner CA, Liu L, Gomis P, Leon A. Emergence delirium in adults in the post-anaesthesia care unit. $\mathrm{Br} \mathrm{J}$ Anaesth 2006;96(6):747-53.

8. Bell C. A Prospective Cohort Study of Emergence Agitation in the Pediatric Postanesthesia Care Unit. Surv Anesthesiol 2004;48(3):136-7.
9. Constant I, Leport Y, Richard P, Moutard ML, Murat I. Agitation and changes of Bispectral IndexTM and electroencephalographic-derived variables during sevoflurane induction in children: clonidine premedication reduces agitation compared with midazolam. Br J Anaesth 2004;92(4):504-11.

10. Lerman J, Davis PJ, Welborn LG, Orr RJ, Rabb M, Carpenter $\mathrm{R}$, et al. Induction, recovery, and safety characteristics of sevoflurane in children undergoing ambulatory surgery: a comparison with halothane. Anesthesiology 1996;84(6):133240.

11. Sachdev P, Kruk J. Restlessness: the anatomy of a neuropsychiatric symptom. Aust N Z J Psychiatry 1996;30(1):38-53.

12. Heier T, Caldwell JE, Warltier DC. Impact of hypothermia on the response to neuromuscular blocking drugs. Anesthesiology 2006;104(5):1070-80.

13. Vanni SM, Braz JR, Módolo NS, Amorim RB, Rodrigues Jr GR. Preoperative combined with intraoperative skin-surface warming avoids hypothermia caused by general anesthesia and surgery. J Clin Anesth 2003;15(2):119-25.

14. Mertens MJ, Olofsen E, Engbers FH, Burm AG, Bovill JG, Vuyk J. Propofol reduces perioperative remifentanil requirements in a synergistic manner: response surface modeling of perioperative remifentanil-propofol interactions. Anesthesiology 2003;99(2):347-59.

This is an open access article distributed under the terms of the Creative Commons Attribution-NonCommercial-ShareAlike 3.0 License, which allows others to remix, tweak, and build upon the work non-commercially, as long as the author is credited and the new creations are licensed under the identical terms

This article was originally published in a special issue, "Evolutionary Strategies in Biomedical Research and Pharmaceutical Sciences” Indian J Pharm Sci 2021:83(3)Spl issue; $83-87$ 